Article

\title{
Experimental Identification of the Optimal Current Vectors for a Permanent-Magnet Synchronous Machine in Wave Energy Converters
}

\author{
Simon Krüner ${ }^{1, *(1)}$ and Christoph M. Hackl ${ }^{2}$ (I) \\ 1 Graduate School of the Munich School of Engineering (MSE), Technical University of Munich (TUM) and \\ SINN Power GmbH, Garching 85748, Germany \\ 2 Department of Electrical Engineering and Information Technology, Munich University of Applied Sciences \\ (MUAS) and MSE-Research Group "Control of Renewable Energy Systems", Technical University of Munich \\ (TUM), Munich 80335, Germany; christoph.hackl@hm.edu \\ * Correspondence: simon.kruener@tum.de; Tel.: +49-171-8033-727
}

Received: 1 February 2019; Accepted: 26 February 2019; Published: 5 March 2019

check for updates

\begin{abstract}
This paper investigates efficiency enhancements in Permanent-Magnet Synchronous Machines (PMSMs) used as generators in wave energy converters. A method is presented, which allows experimental identification of the optimal current vectors leading to minimal losses and maximum efficiency. Iron and inverter losses are considered. The proposed identification method is generic and is applicable to any PMSM used as a generator. The obtained results are compared to the well-known Maximum Torque per Current (MTPC) strategy. Two MTPC strategies are investigated: (i) MTPC using linearised flux linkages; and (ii) MTPC using measured, nonlinear flux linkages. For both MTPC strategies, the influence of the Voltage Source Inverter (VSI) is taken into account. All measurements are performed on a simple and cheap industrial-like test bench. All three presented methods lead to increased efficiency. The best efficiency is obtained by the proposed maximum efficiency strategy, where iron and inverter losses are taken into account by proper measurement of the optimal current vectors.
\end{abstract}

Keywords: permanent-magnet synchronous machine; maximum torque per current; optimal control; maximum efficiency; loss minimization; flux linkage measurement; generator operation

\section{Introduction}

Electrical drive systems are becoming increasingly important for renewable energy systems, due to their flexibility and high dynamic performance. In particular, Permanent-Magnet Synchronous Machines (PMSM) are used for their high power density and efficiency. In this publication, a PMSM, which is installed in a wave energy converter, is analysed. Small-scale wind or water turbines can also provide alternative applications.

\subsection{Motivation}

The startup company SINN Power GmbH has developed a wave energy converter and has recently installed its third prototype. For this purpose, a generator unit was developed, which can withstand enormous environmental influences. The generator unit and the prototype of a single module of the power plant, which is mounted on the harbour wall of Iraklio on the Greek island of Crete, is shown in Figure 1. In this contribution, only the generator unit is investigated, with the aim of optimizing its efficiency. The interface of the wave energy converter control system to the generator unit is the torque, resulting in an optimal damping force of the point absorber. The focus of this paper is the optimal current control of the generator, for a given reference torque. 


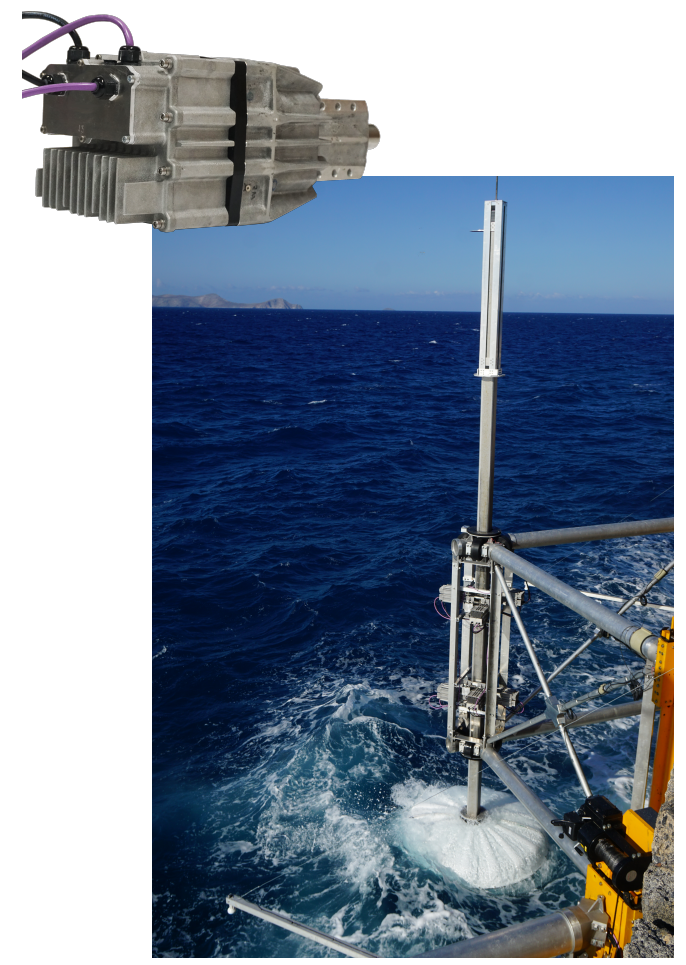

Figure 1. Picture of the SINN Power GmbH prototype in Crete and the analysed generator unit.

In order to achieve high efficiency and produce as much energy as possible, the Maximum Torque per Current (MPTC) strategy can be implemented. This strategy is often called Maximum Torque per Ampere (MTPA) but, as explained in [1], the terminology MTPC might be more appropriate.

The MTPC strategy is based on the properties of the electrical machine, in which flux linkages and differential inductances are nonlinear functions of the currents. This gives an infinite number of current vectors producing the same torque. The electrical losses can be divided into copper losses and iron losses, of which copper losses account for a large proportion [2] (Section 16.7.1). The idea of MTPC is to minimize the current amplitude for a certain torque, to reduce the copper losses in the stator windings. For this, the generally nonlinear flux linkage has to be known [1,3-5].

A vectorial approach with a high-order sliding mode current control was applied in [6-8] to simplify the generation of the optimal reference current for multiphase PMSM. The reference current was chosen to be collinear with the induced voltage (electromotive force), which produced a constant and smooth torque, even under open-phase faults.

In [9-11] signal injection was used to track the MTPC hyperbola online. A different approach to speed control was applied in [12], where the DC-link quantities were measured to maximize the efficiency during operation in the steady-state conditions.

To identify and compensate for the iron losses, a precise procedure has to be followed, in which sensitive measurement equipment with a high resolution is needed. The stator voltage and current have to be measured correctly and synchronously which, due to the switching noise, is not trivial. In $[13,14]$, iron losses were neglected when determining the flux linkages because of slow speeds, whereas in $[15,16]$ iron losses were identified by alternating between motor and generator operation with a corresponding flux linkage.

If iron losses are also taken into account for the increase in efficiency, the method is called Loss Minimization (LM) [17-20]. In this case, the parameters, such as the flux linkage and the iron loss resistance, have to be known. 


\subsection{Contribution of the Paper}

In this paper, the complete drive system is considered, in order to find the optimal current vector to maximize the efficiency. This includes the copper and iron losses of the machine, as well as the whole inverter. Field weakening or Maximum Torque per Voltage (MTPV) are not considered, because the rotor speed is slow for the considered operation of the wave energy converter.

For MTPC, the flux linkage maps are measured to take the nonlinearities of the machine into account. For this measurement, the stator voltages are measured with an analog filter and sampled with an industrial microcontroller of the inverter. Averaging of all measured quantities over several seconds, where multiple mechanical revolutions are made, helps to reduce the error of spatial harmonics and noise.

A method is presented to directly measure the point of minimal losses and maximum efficiency, without knowledge of the nonlinear flux linkages or the iron loss resistance. Therefore, the current vectors that produce a certain torque are measured in a desired range. Using the ratio of the DC-link power to the mechanical power on the shaft to maximize the overall efficiency gives the optimal current vector. With this procedure, all losses are taken into account, and errors, such as misalignment of the positioning sensor, are compensated for; additionally, complicated measurements, for example that of the stator voltage, can be avoided. The measurement of the DC-link quantities does not require high-quality evaluation electronics.

All measurements are done in steady-state and in generator mode. As the periods of the waves are very slow compared to the dynamics of the generator's current control loops, the current dynamics can be neglected and the optimal current vector, from the steady-state measurements, can be used.

\subsection{Outline of the Paper}

First, the theoretical background of MTPC is explained and exemplified for linearised flux linkages. Then, the influence of the inverter on efficiency is estimated and it is explained why it is true to obtain the maximum power out of a generator when the stator currents are reduced. Section 3.2 describes how to measure the flux linkage maps and how to obtain the nonlinear MTPC hyperbola in the rotor fixed $(d, q)$-plane. This is followed by the direct measurement of the maximum efficiency, where no flux linkages are needed. In Section 4, the results of all three methods are shown and compared.

\section{Theory}

This section presents the theory of MTPC and explains why it is useful for minimizing the current in the generator and motor operation, to extract the maximum power. The overall aim in generator operation is to maximize the output power for a given torque and speed. Here, the DC-link power is considered. This includes the electrical machine, as well as the inverter behavior.

\subsection{Model of a Synchronous Machine without Iron Losses}

In the following, the subscript of a physical quantity indicates whether it is related to the stator (s) or rotor ( $\mathrm{r}$ ). The superscript refers to the coordinate system (reference frame), or to a coordinate itself.

To obtain an expression for the active power, a model of an electrical machine has to be used. For this model, the following assumptions are imposed:

- $\quad$ The three phases of the electrical machine are star-connected (i.e., $i_{\mathrm{s}}^{\mathrm{a}}(t)+i_{\mathrm{s}}^{\mathrm{b}}(t)+i_{\mathrm{s}}^{\mathrm{c}}(t)=0$ ).

- The machine is symmetrical.

- Only the fundamentals are considered and spatial harmonics are neglected.

- Iron losses are neglected. 
The stator voltages of a PMSM in the synchronously rotating orthogonal $k=(d, q)$-reference frame, where the $d$-axis is aligned with the permanent-magnet flux linkage, are given as follows [2,21,22]:

$$
\left.\begin{array}{l}
u_{\mathrm{s}}^{d}=R i_{\mathrm{s}}^{d}+\frac{\mathrm{d}}{\mathrm{d} t} \psi_{\mathrm{s}}^{d}-\omega \psi_{\mathrm{s}}^{q} \\
u_{\mathrm{s}}^{q}=R i_{\mathrm{s}}^{q}+\frac{\mathrm{d}}{\mathrm{d} t} \psi_{\mathrm{s}}^{q}+\omega \psi_{\mathrm{s}}^{d},
\end{array}\right\}
$$

with stator voltages $\boldsymbol{u}_{\mathrm{s}}^{k}=\left(u_{\mathrm{s}}^{d}, u_{\mathrm{s}}^{q}\right)^{\top}$, stator currents $i_{\mathrm{s}}^{k}=\left(i_{\mathrm{s}}^{d}, i_{\mathrm{s}}^{q}\right)^{\top}$, stator flux linkages $\psi_{\mathrm{s}}^{k}=\left(\psi_{\mathrm{s}}^{d}, \psi_{\mathrm{s}}^{q}\right)^{\top}$, and the electrical angular frequency $\omega=n_{\mathrm{p}} \omega_{\mathrm{m}}$, where $n_{\mathrm{p}}$ is the pole pair number and $\omega_{\mathrm{m}}$ is the mechanical angular frequency. The flux linkage $\psi_{\mathrm{s}}^{k}=\psi_{\mathrm{s}}^{k}\left(i_{\mathrm{s}}^{k}\right)$ is, in general, a nonlinear function of the currents.

Considering just the steady-state operation, all time derivatives become zero and the equation for the stator voltages can be simplified:

$$
\left.\begin{array}{l}
u_{\mathrm{s}}^{d}=R i_{\mathrm{s}}^{d}-\omega \psi_{\mathrm{s}}^{q} \\
u_{\mathrm{s}}^{q}=R i_{\mathrm{s}}^{q}+\omega \psi_{\mathrm{s}}^{d} .
\end{array}\right\}
$$

The machine torque is given by

$$
m_{\mathrm{m}}=\frac{3}{2} n_{\mathrm{p}}\left(i_{\mathrm{s}}^{k}\right)^{\top} J \psi_{\mathrm{s}}^{k}=\frac{3}{2} n_{\mathrm{p}}\left(\psi_{\mathrm{s}}^{d} i_{\mathrm{s}}^{q}-\psi_{\mathrm{s}}^{q} i_{\mathrm{s}}^{d}\right)
$$

where $J=\left[\begin{array}{cc}0 & -1 \\ 1 & 0\end{array}\right]$. Because both currents influence the torque, there exist an infinite number of current vectors $i_{\mathrm{s}}^{k}$ producing the same torque. The machine characteristics, which are mainly given by the flux linkages, define the sensitivity of each current component.

\subsection{Simplified Modelling of the Voltage Source Inverter}

To estimate the inverter's influence, one of the three half-bridges is shown in Figure 2. Figure 2a shows a half-bridge with the two MOSFETs. We have that $s \in\{0,1\}$ represents the switching state of the upper MOSFET and $\bar{s}=1-s$ of the lower one. The bridge works in complementary mode, meaning that if the upper MOSFET is on $(s=1)$, the lower one has to be off $(\bar{s}=0)$, and vice versa. If the MOSFETs are ideal, the voltage $u_{\mathrm{s} 0}$ is $u_{\mathrm{dc}}$ if $s=1$ and $0 \mathrm{~V}$ if $s=0$. However, the current through the MOSFET causes a change of the voltage. Note that the voltage $u_{\mathrm{s} 0}$ is different to the stator voltage.

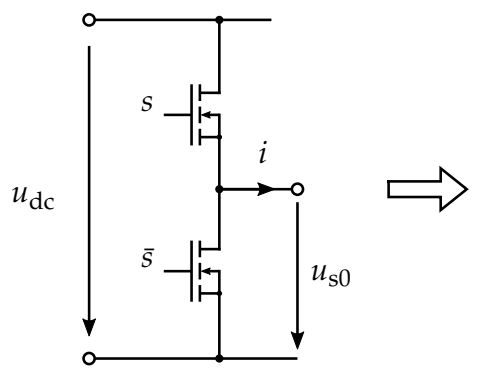

(a)

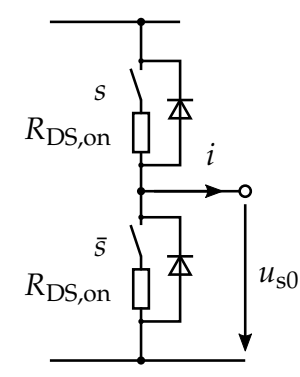

(b)

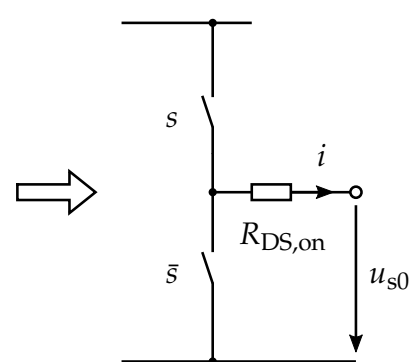

(c)

Figure 2. One half-bridge of the voltage source inverter with (a) the two MOSFETs, (b) the equivalent circuit of the MOSFETs and (c) the simplification of the half bridge.

In order to avoid a short circuit, there has to be a period between turning on and off where neither switch is turned on. This time period is called dead time. Figure $2 \mathrm{~b}$ illustrates the bridge with the 
equivalent circuit of the MOSFETs with the drain-source on resistor $R_{\mathrm{DS} \text {, on }}$ and the body diode. The parasitic capacitors are not considered. If the MOSFET is on, the switch is closed and only $R_{\mathrm{DS} \text {,on }}$ causes conduction losses. The phase current $i$ flows through the MOSFET which is turned on. During the dead time, the current flows through the upper diode if $i$ is negative and through the lower one if $i$ is positive. Then, the diodes cause losses and change the voltage $u_{\mathrm{s} 0}$. Additionally, the switching itself causes losses and a not-instant change in the stator voltage [23,24].

To create a defined flux linkage in the machine, a certain voltage has to be applied for a defined amount of time. In general, the flux linkage is the integral of the voltage over time, so the voltage time area is of importance in creating the desired flux linkage. As the dead time is very short, compared to the switching period, the dead time, the influence of the body diodes, and the switching behavior are neglected. The resistor $R_{\mathrm{DS} \text {,on }}$ mainly affects the stator voltage. Figure $2 \mathrm{c}$ represents the simplification of the half bridge. As the current $i$ flows either through the upper or the lower switch, the resistor $R_{\mathrm{DS} \text {,on }}$ can be considered as part of the phase and, thus, in series with the stator resistor $R_{\mathrm{S}}$ and the resistor $R_{\mathrm{c}}$ of the cable, which connect the inverter to the machine. All resistors

$$
R=R_{\mathrm{S}}+R_{\mathrm{DS}, \text { on }}+R_{\mathrm{c}}
$$

are summed up and considered in the machine model. Consideration of all resistors is important, not only for the calculation of the flux linkages, but also for the controller design. Especially for small machines, the resistor $R_{\mathrm{DS} \text {,on }}$, in comparison to the stator resistance $R_{\mathrm{S}}$, is not negligible, unlike the cable resistance $R_{\mathrm{c}}$ if the cable is short enough.

\subsection{Power Analysis}

In the half-bridge, only the ideal switches, which define the stator voltage, remain. By adding the MOSFET resistor to the stator resistor, the flux-building voltage can be calculated more accurately. Moreover, the active power $P_{\mathrm{el}}$, in the three phases, is equal to the DC-link power; that is,

$$
P_{\mathrm{dc}}=u_{\mathrm{dc}} i_{\mathrm{dc}}=\left(\boldsymbol{u}_{\mathrm{s}}^{a b c}\right)^{\top} \boldsymbol{i}_{\mathrm{s}}^{a b c}=P_{\mathrm{el}},
$$

with the stator voltages $u_{\mathrm{s}}^{a b c}=\left(u_{\mathrm{s}}^{\mathrm{a}}, u_{\mathrm{s}}^{\mathrm{b}}, u_{\mathrm{s}}^{\mathrm{c}}\right)^{\top}$ and stator currents $i_{\mathrm{s}}^{a b c}=\left(i_{\mathrm{s}}^{\mathrm{a}}, i_{\mathrm{s}}^{\mathrm{b}}, i_{\mathrm{s}}^{\mathrm{c}}\right)^{\top}$ in the three-phase $(a, b, c)$-reference frame.

The active power can be computed by

$$
P_{\mathrm{el}}=\left(\boldsymbol{u}_{\mathrm{s}}^{a b c}\right)^{\top} i_{\mathrm{s}}^{a b c}=\frac{3}{2}\left(\boldsymbol{u}_{\mathrm{s}}^{k}\right)^{\top} i_{\mathrm{s}}^{k}=\frac{3}{2}\left(u_{\mathrm{s}}^{d} i_{\mathrm{s}}^{d}+u_{\mathrm{s}}^{q} i_{\mathrm{s}}^{q}\right) .
$$

Inserting (2) into (6) and rearranging leads to

$$
\begin{aligned}
P_{\mathrm{el}} & =\frac{3}{2} R\left(\left(i_{\mathrm{s}}^{d}\right)^{2}+\left(i_{\mathrm{s}}^{q}\right)^{2}\right)+\frac{3}{2} \omega\left(\psi_{\mathrm{s}}^{d} i_{\mathrm{s}}^{q}-\psi_{\mathrm{s}}^{q} i_{\mathrm{s}}^{d}\right) \\
& \stackrel{(3)}{=} \underbrace{\frac{3}{2} R\left(\left(i_{\mathrm{s}}^{d}\right)^{2}+\left(i_{\mathrm{s}}^{q}\right)^{2}\right)}_{=: P_{\mathrm{Cu}}}+\underbrace{\omega_{\mathrm{m}} m_{\mathrm{m}}}_{=: P_{\mathrm{m}}} .
\end{aligned}
$$

The active power $P_{\mathrm{el}}$ is composed of the copper losses $P_{\mathrm{Cu}}$ and the internal mechanical power $P_{\mathrm{m}}$. The MTPC algorithm should compute the optimal current vector for a given torque to minimize the power losses. The MTPC hyperbola in the $(d, q)$-plane is given by the set of all optimal current vectors for all possible torques. Considering the speed and torque as constant, Equation (7) shows that solely the copper losses $P_{\mathrm{Cu}}$ affect the power $P_{\mathrm{el}}$. As seen in (3), several current vectors $i_{\mathrm{s}}^{k}$ can produce the same torque, but only the current with the minimal amplitude gives the optimal solution. In generator 
operation, where $P_{\mathrm{m}}$ and $P_{\mathrm{el}}$ are negative, the copper losses reduce the effective output power. In motor operation, where $P_{\mathrm{m}}$ is positive, the copper losses increase the input power.

\section{Methods for Efficiency Enhancement}

In this section, three methods for efficiency enhancement are described. The first two methods are about the MTPC strategy, assuming linear flux linkages in the first and nonlinear flux linkages in the second. The third method describes a measurement to find the current vectors with maximum efficiency.

\subsection{Maximum Torque Per Current for Linear Flux Linkages}

In order to clarify the algorithm, the MTPC hyperbola will be calculated numerically with the linearised flux linkages. For PMSMs, the following well-known approximation

$$
\left.\begin{array}{l}
\psi_{\mathrm{s}}^{d} \approx L_{\mathrm{s}}^{d} i_{\mathrm{s}}^{d}+\psi_{\mathrm{pm}} \\
\psi_{\mathrm{s}}^{q} \approx L_{\mathrm{s}}^{q} i_{\mathrm{s}}^{q}
\end{array}\right\}
$$

is made $[2,15,21,25] . L_{\mathrm{s}}^{d}$ and $L_{\mathrm{s}}^{q}$ are the stator inductances of the $d$ - and $q$-axis, respectively, and $\psi_{\mathrm{pm}}$ is the permanent-magnet flux linkage. The mutual inductance, which describes the cross-coupling between the $d$ - and $q$-axis, is neglected. By inserting (8) into (3), the machine's torque can be approximated by the expression

$$
m_{\mathrm{m}} \approx \underbrace{\frac{3}{2} n_{\mathrm{p}} \psi_{\mathrm{pm}} i_{\mathrm{s}}^{q}}_{=m_{\mathrm{el}}}+\underbrace{\frac{3}{2} n_{\mathrm{p}}\left(L_{\mathrm{s}}^{d}-L_{\mathrm{s}}^{q}\right) i_{\mathrm{s}}^{d} i_{\mathrm{s}}^{q}}_{=m_{\mathrm{re}}} .
$$

The torque can be divided into electro-magnetic torque $m_{\mathrm{el}}$ and reluctance torque $m_{\mathrm{re}}$. The reluctance torque only exists for anisotropic machines, where $L_{\mathrm{s}}^{d} \neq L_{\mathrm{s}}^{q}$. This results in an extra degree of freedom in the torque equation, which only then allows an optimized control as MTPC. Solving this equation for $i_{\mathrm{S}}^{q}$ leads to

$$
i_{\mathrm{s}}^{q}=\frac{m_{\mathrm{m}}}{\frac{3}{2} n_{\mathrm{p}}\left(\psi_{\mathrm{pm}}+\left(L_{\mathrm{s}}^{d}-L_{\mathrm{s}}^{q}\right) i_{\mathrm{s}}^{d}\right)} .
$$

For a given torque, all current vectors can be calculated numerically in a sensible range and resolution. The one with minimal amplitude $\left\|i_{\mathrm{s}}^{k}\right\|=\sqrt{\left(i_{\mathrm{s}}^{d}\right)^{2}+\left(i_{\mathrm{s}}^{q}\right)^{2}}$ can be picked for the maximum torque per current ratio. For implementation, the results for a desired torque range can be stored in a lookup table. Figure 3 shows the third quadrant in the $(d, q)$-plane, where the machine operates as a generator and the rotor speed is positive. 


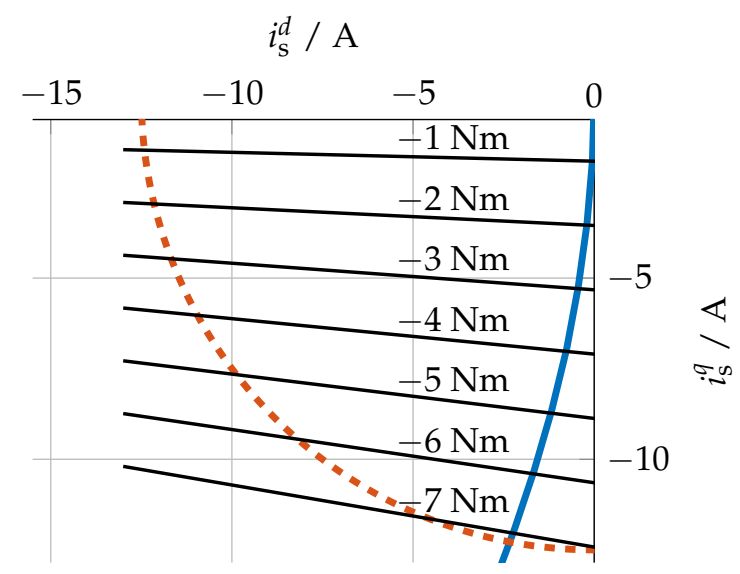

Figure 3. Illustration of the torque contour lines (-), the current limit $(-=-)$, and the numerically calculated Maximum Torque per Current (MTPC) hyperbola with linearised flux linkages $(-)$.

The black lines are the contour lines calculated with (10), where the torque is constant for each line. The blue line represents the MTPC hyperbola, which connects the points with the minimum current amplitude of each contour line. The dashed red line is the current limitation, given by

$$
\sqrt{\left(i_{\mathrm{s}}^{d}\right)^{2}+\left(i_{\mathrm{s}}^{q}\right)^{2}} \leq i_{\max }
$$

Table 1 shows the linearised parameters of the considered electrical machine. The solution for a given torque can also be calculated analytically. A unified theory for optimal feedforward torque control with non-negligible mutual inductance was presented in [1].

Table 1. Parameters of the electrical machine.

\begin{tabular}{lcc}
\hline Name & Parameter & Value \\
\hline Number of pole pairs & $n_{\mathrm{p}}$ & 5 \\
Gear ratio & $g_{\mathrm{r}}$ & 8 \\
Stator resistance at $20^{\circ} \mathrm{C}$ & $R_{\mathrm{s}, 20}$ & $396 \mathrm{~m} \Omega$ \\
Stator resistance at $120^{\circ} \mathrm{C}$ & $R_{\mathrm{s}, 120}$ & $570 \mathrm{~m} \Omega$ \\
Drain-source on resistance & $R_{\mathrm{DS}, \mathrm{on}}$ & $60 \mathrm{~m} \Omega$ \\
Resistance of the cable & $R_{\mathrm{c}}$ & $12 \mathrm{~m} \Omega$ \\
Permanent-magnet flux linkage & $\psi_{\mathrm{pm}}$ & $75.79 \mathrm{mVs}$ \\
$d$-Inductance & $L_{\mathrm{s}}^{d}$ & $4.5 \mathrm{mH}$ \\
$q$-Inductance & $L_{\mathrm{s}}^{q}$ & $5.7 \mathrm{mH}$ \\
\hline
\end{tabular}

\subsection{Maximum Torque Per Current for Nonlinear Flux Linkages}

The MTPC hyperbola can also be determined by inserting the nonlinear flux linkages into the torque Equation (3) and searching for the current vector with the smallest amplitude for a certain torque. The flux linkage is measured in steady-state operation. Therefore, the Equation (2) is solved for the flux linkages, which yields

$$
\psi_{\mathrm{s}}^{d}=\frac{u_{\mathrm{s}}^{q}-R i_{\mathrm{s}}^{q}}{\omega} \quad \text { and } \quad \psi_{\mathrm{s}}^{q}=-\frac{u_{\mathrm{s}}^{d}-R i_{\mathrm{s}}^{d}}{\omega} .
$$

To obtain the desired maps of the flux linkages, $\psi_{\mathrm{s}}^{k}=\left(\psi_{\mathrm{s}}^{d}, \psi_{\mathrm{s}}^{q}\right)^{\top}$ has to be calculated for each point defined by the current $i_{\mathrm{s}}^{k}=\left(i_{\mathrm{s}}^{d}, i_{\mathrm{s}}^{q}\right)^{\top}$ in a useful grid. At each point, the current and the voltage have to be measured and logged. To eliminate unwanted signals, such as noise and spatial or inverter harmonics, averaging of the signals is needed. Due to the low resolution of the Analog 
to Digital Converter (ADC), which causes a high noise ratio, and the relatively slow Controller Area Network (CAN) communication, where the measured quantities are sent to the Programmable Logic Control (PLC) for data logging, the chosen averaging has to be long enough. In this case, the signals are averaged over more than a minute.

The currents $i_{\mathrm{s}}^{k}$ are measured for the controller feedback and can be taken from there. The rotor speed $\omega_{\mathrm{m}}$ is held constant by the drive machine, but is nevertheless measured by the torque sensor to compensate for variations. The resistor $R$ can be measured in advance with direct current measurement. The temperature dependency has to be compensated. This can be done with the temperature sensor between the stator windings. When measuring the resistance at different stator temperatures, a linear dependency can be expected, which fits to the temperature coefficient of copper. It is important to measure the resistance with a homogeneous temperature distribution in the stator, which is given, for example, after a long-run test of the machine at a constant operation point. For the measurements at the test bench, the resistor can be adapted by the measured temperature.

However, it has turned out that the temperature transition between the windings and the sensor is still too slow to compensate for the resistance during rapid temperature changes. Consequently, it is essential to make the measurement at nearly constant temperature. At the beginning, there has to be a heating phase where the whole machine is warmed up to the operating temperature. In order to hold this temperature constant during the measurement, it is necessary to add heating and cooling phases to the procedure. Additionally, the permanent magnet flux linkage is dependent on the temperature, which is not easy to compensate for, making the warming phase especially important $[13,15]$.

There are two ways to obtain the stator voltage $u_{\mathrm{s}}^{k}=\left(u_{\mathrm{s}}^{d}, u_{\mathrm{s}}^{q}\right)^{\top}$. It can either be taken as the reference voltage of the controller or measured directly by the microcontroller. Over an analog low pass filter, the phase voltages are connected to the ADCs of the microcontroller.

The analog filter is designed to damp the switching frequency and leave the amplitude of the signals of interest unaffected. To obtain the correct voltage vector $\boldsymbol{u}_{\mathrm{s}}^{k}$, the phase lag, and the delay of the ADC have to be compensated for. The measured stator voltage $\boldsymbol{u}_{\mathrm{s}, \mathrm{m}}^{k}$ is delayed and must be compensated for by applying the park transformation with

$$
u_{\mathrm{s}}^{k}=T_{\mathrm{p}}\left(\phi_{\mathrm{d}}\right) u_{\mathrm{s}, \mathrm{m}}^{k}
$$

where $\phi_{\mathrm{d}}$ is the angle related to the delay. So, it is returned to the time it was measured.

The phase lag of the filter can be determined with the right measurement equipment. Another way is to calculate the theoretical phase lag from the transfer function and correct it by having a closer look at the resulting flux linkage. Due to the definition of the $(d, q)$-reference frame, which determines that the $d$-axis is aligned with the permanent-magnet flux linkage

$$
\psi_{\mathrm{s}}^{k}\left(i_{\mathrm{s}}^{k}=0\right)=\left(\begin{array}{c}
\psi_{\mathrm{pm}} \\
0
\end{array}\right)
$$

there should be no flux linkage in $\psi_{\mathrm{s}}^{q}$ when the currents are zero [15]. If the cross coupling is negligible, then $\psi_{\mathrm{s}}^{q}$ should be zero only if $i_{\mathrm{s}}^{q}=0 \mathrm{~A}$. Additionally, the measured torque should fit the torque which is computed, by inserting the flux linkage in Equation (3). Under these conditions, the angle can be adapted until the contour line for $\psi_{\mathrm{s}}^{q}=0 \mathrm{Vs}$ lies on the $q$-axis and the calculated torque fits the measured one. It is possible that there is still an offset, due to measurement errors. By adding this offset to $\psi_{\mathrm{s}}^{q}$, the error can be reduced. The offset of $\psi_{\mathrm{s}}^{d}$ is the permanent-magnet flux linkage $\psi_{\mathrm{pm}}$, which can also be corrected if a more accurate measurement has been made before by an open circuit measurement.

If the stator voltage is calculated based on the reference voltage of the controller output, the dead time has to be compensated for. Due to the condition in Equation (14) and the resulting torque, it was 
revealed that the calculated voltage, and thus the resulting flux linkage, is not plausible. Because of this, the measured voltages are taken for the following calculations.

Because the Device Under Test (DUT) can only operate as a generator, the product $\omega_{\mathrm{m}} m_{\mathrm{m}}$ must be negative, limiting the measurement range. The current vector, which produces a certain torque, is very dependent on the flux linkage, so the transition between the generator and motor operation area in the $(d, q)$-plane is different for each machine. Considering the torque Equation (9) with the linearized flux linkage, the operation areas can be estimated by solving the equation for $m_{\mathrm{m}}=0 \mathrm{Nm}$. The four quadrants where the torque is positive or negative are divided by the transient lines

$$
i_{\mathrm{s}}^{q}=0 \mathrm{~A} \quad \text { and } \quad i_{\mathrm{s}}^{d}=-\frac{\psi_{\mathrm{pm}}}{L_{\mathrm{s}}^{d}-L_{\mathrm{s}}^{q}} .
$$

For the considered DUT, $L_{\mathrm{s}}^{d}$ is smaller than $L_{\mathrm{s}}^{q}$ and, hence, $i_{\mathrm{s}}^{d}$ is positive. If the difference between $L_{\mathrm{s}}^{d}$ and $L_{\mathrm{s}}^{q}$ is small, because the machine is not anisotropic, this transient line is at a very high current, even beyond the current limit $i_{\max }$. Moreover, it is more likely that the voltage limit

$$
\sqrt{\left(u_{\mathrm{s}}^{d}\right)^{2}+\left(u_{\mathrm{s}}^{q}\right)^{2}} \leq u_{\max }
$$

does not allow driving of high positive direct currents $i_{\mathrm{s}}^{d}$, as shown in Figure 4. Consequently, some data points could not be measured correctly and were not considered in the following results. Note that $u_{\max }$ depends on the modulation technique [2] (Section 14.3).

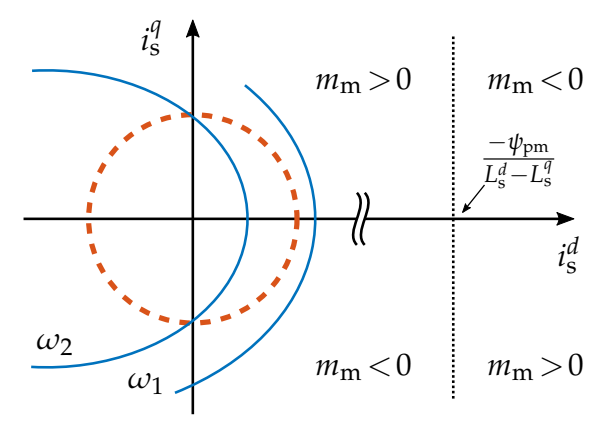

Figure 4. Illustration of the operation areas with the transient line $(\cdots \cdots)$, the current limit $(--")$, and the voltage limit ( - ) for two different speeds $\omega_{1}<\omega_{2}$.

Here, the current area in the $(d, q)$-plane is, besides the voltage limit, mainly limited to $i_{\mathrm{s}}^{q}<0 \mathrm{~A}$ for a positive angular speed $\omega$. Due to the rotor symmetry, the flux linkage is symmetrical to the $d$-axis. Hence, it is possible to expand the flux linkage map for $i_{\mathrm{s}}^{q}>0 \mathrm{~A}$ by mirroring the data points. However, it has to be considered that the iron losses falsify the measurement and the symmetry characteristics. The iron losses are caused by an internal current flow, which differs the magnetization current from the measured one in phases. Since the impact of the iron losses is more significant at high rotor speeds, the measurements should be done at lower speed [13]. If the iron losses are not negligible, they have to be considered in the measurement of the flux linkage $[15,16]$.

Figure 5 shows the measured flux linkage map of $\psi_{\mathrm{s}}^{d}$ and $\psi_{\mathrm{s}}^{q}$, where the part with $i_{\mathrm{s}}^{q}>0 \mathrm{~A}$ was mirrored. Figure $5 \mathrm{a}, \mathrm{c}$ show the top view of the flux linkage, with contour lines of constant flux. Note that the contour line in Figure $5 \mathrm{c}$ for $\psi_{\mathrm{s}}^{q}=0 \mathrm{Vs}$ lies on the $q$-axis due to the correct compensation of the phase lag and offset, as described before. Figure 5b,d show the same flux linkage as a 3D plot.

The MTPC hyperbola can be found by calculating the torque with Equation (3) and the nonlinear flux linkage. Interpolating between the data points, the torque contour lines can be calculated, and the current vector with the minimal amplitude can be picked. This leads to a more accurate representation 
of the produced torque in the machine and, thus, a better solution for the MTPC hyperbola. The results are described in Section 4.

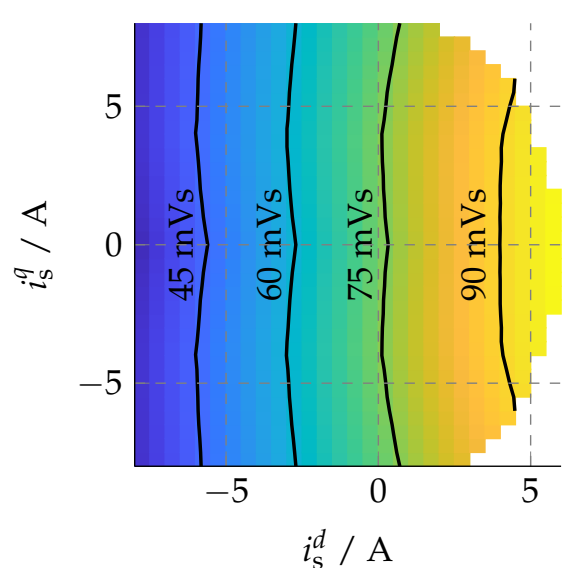

(a)

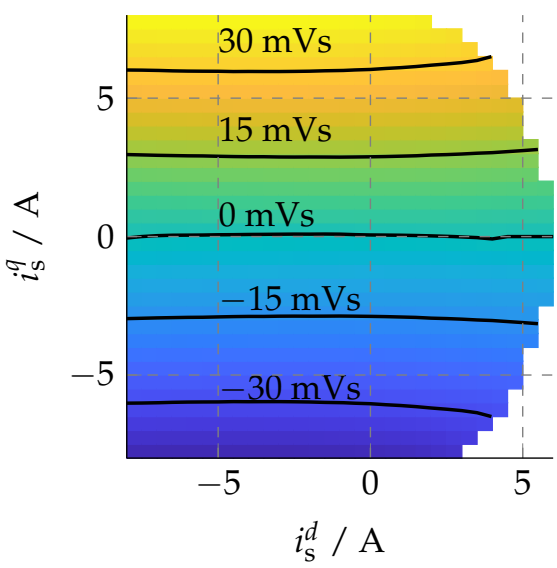

(c)

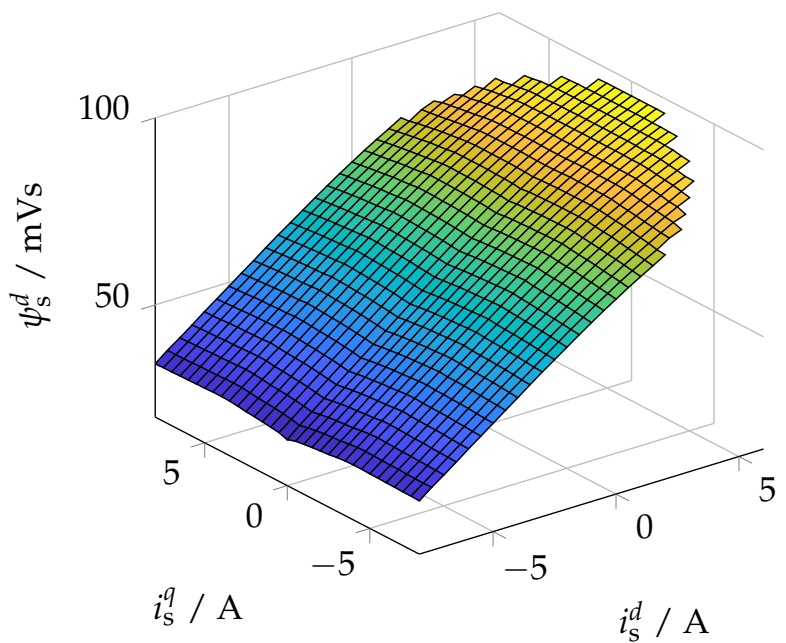

(b)

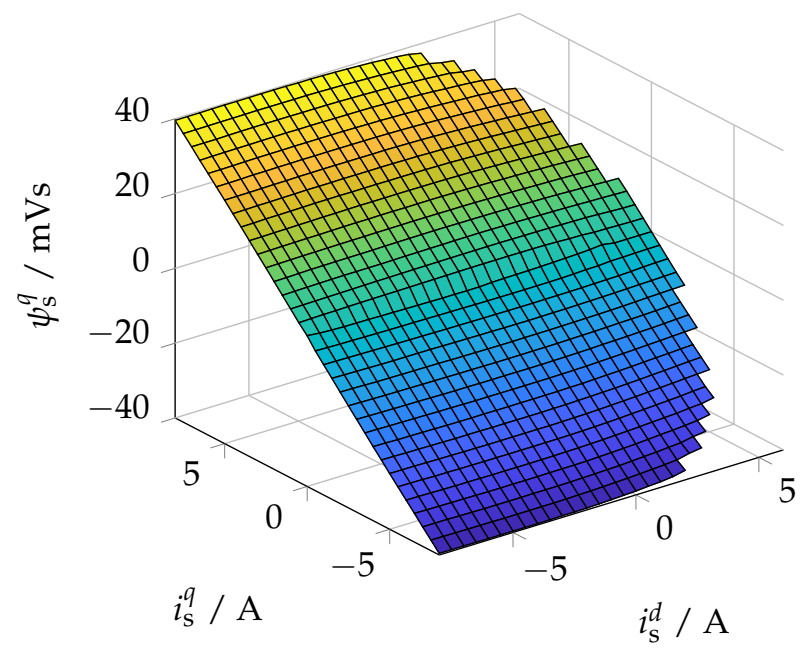

(d)

Figure 5. Measured flux linkage maps. (a) Flux linkage $\psi_{\mathrm{s}}^{d}$ with black contour lines of constant flux linkage; (b) Flux linkage $\psi_{\mathrm{s}}^{d}$ in a 3D plot; (c) Flux linkage $\psi_{\mathrm{s}}^{q}$ with black contour lines of constant flux linkage; and (d) Flux linkage $\psi_{\mathrm{s}}^{q}$ in a 3D plot.

\subsection{Direct Measurement of the Current Vector with the Maximum Efficiency}

In the following, a measurement method is developed to determine the current vectors with the maximum efficiency. For that, an extra control loop for the torque is superimposed on the $q$-component of the current. The signal flow diagram of this control system is shown in Figure 6.

The idea is to drive through the contour line of constant torque in the $(d, q)$-plane and find the point of maximum output power in the DC-link by measuring it. The torque contour lines from the flux linkages are interpolated and are, therefore, not accurate enough to determine the correct point of maximum efficiency.

These measurements are also done in steady-state at constant speed. The torque can be set with the reference shaft torque $m_{\mathrm{s}, \text { ref }}$. The outer torque control loop sets the right current $i_{\mathrm{s}}^{q}$ to keep the torque constant. The current $i_{\mathrm{s}}^{d}$ is changed stepwise. After the settling time, the controller is turned 
off and the momentary reference currents are kept constant during the measurement. As before, the measured quantities are averaged. After the desired range is measured, the torque can be set to the next contour line. It is reasonable to vary $i_{\mathrm{s}}^{d}$ and let $i_{\mathrm{s}}^{q}$ be controlled, since the torque is much more sensitive to $i_{\mathrm{s}}^{q}$ than to $i_{\mathrm{s}}^{d}$.

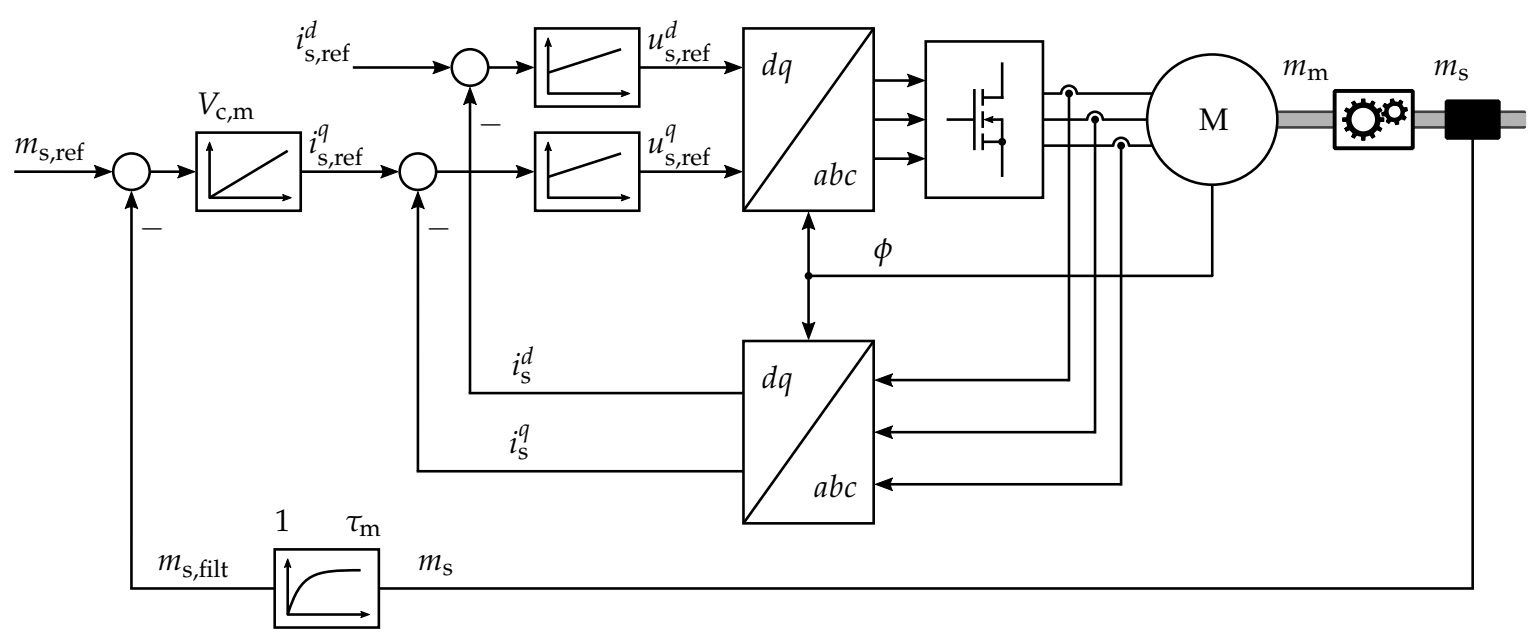

Figure 6. Signal flow diagram of the current control loops with the outer torque control loop.

To remove noise and harmonics due to rotation unbalance in the torque signal, it is useful to filter it. To obtain a smooth signal, the cutoff frequency has to be very low. This leads to a very high time constant, which dominates the control system. Hence, a simple integrating controller with the transfer function

$$
F_{\mathrm{c}, \mathrm{m}}(s)=V_{\mathrm{c}, \mathrm{m}} \frac{1}{s}
$$

is used, to set the reference current $i_{\mathrm{s}, \text { ref }}^{q}$. According to ([2], Sec. 3.4), the controller gain $V_{\mathrm{c}, \mathrm{m}}$ is chosen as

$$
V_{\mathrm{c}, \mathrm{m}}=\frac{1}{2 \tau_{\mathrm{m}} V_{m}}
$$

where $\tau_{\mathrm{m}}$ is the time constant of the torque filter with the cutoff frequency

$$
f_{\mathrm{c}, \mathrm{m}}=\frac{1}{2 \pi \tau_{\mathrm{m}}} .
$$

The gain

$$
V_{\mathrm{m}}=\frac{m_{\mathrm{s}}}{i_{\mathrm{s}}^{q}} \approx \frac{3}{2} n_{\mathrm{p}} g_{\mathrm{r}} \psi_{\mathrm{pm}}
$$

is the ratio of torque $m_{\mathrm{s}}$ at the shaft and current $i_{\mathrm{s}}^{q}$. This approximation comes from Equation (9) by assuming that $L_{\mathrm{s}}^{d}=L_{\mathrm{s}}^{q}$. The reluctance torque can be seen as a disturbance, which will be compensated for by the controller. A larger disturbance is caused by the mechanical losses, such as friction. Here, $g_{\mathrm{r}}$ is the gear ratio, which describes the ratio of the machine torque $m_{\mathrm{m}}$ to shaft torque $m_{\mathrm{s}}$, which is the measured torque with

$$
m_{\mathrm{s}}=g_{\mathrm{r}} m_{\mathrm{m}}-m_{\mathrm{f}} .
$$


Note that $m_{\mathrm{m}}$ is the produced torque of the generator. The torque $m_{\mathrm{f}}$, caused by mechanical losses, is a nonlinear function of the time, temperature, speed, and the shaft torque itself [26] (Section 11.1.5).

For this type of measurement, it is important to stay on the contour line with the constant machine torque $m_{\mathrm{m}}$. The contour line can be measured by keeping $m_{\mathrm{s}}$ constant only if $m_{\mathrm{f}}$ stays unchanged during the measurement. As the measurements are done at constant speed and torque, the main influence on the mechanical losses is the temperature. This can be explained by the change in the viscosity of the different greases and the gear oil. When the temperature rises, they become more fluid, reducing the friction [26] (Section 11.1.5).

Additionally, the stator resistor, and thus the copper losses, increase with the temperature. To determine the point of maximal output power, the electrical losses have to stay constant as well.

Again, it is mandatory to heat up the whole machine before starting the measurement. With heating and cooling phases in between the measurement points, the temperature stays almost constant. As the stator temperature rises faster than the mechanical part, the cooling phase can be achieved by merely setting the currents to zero and letting the machine rotate. This cools the stator down and the gearbox and bearings hold their temperature. After the settling time, when the torque controller is turned off, the measurement with the averaging should not take too long, being done before the temperature changes again. Otherwise, the torque will also not remain constant. If the measured torque deviates too much from the reference torque, the measurement must be repeated. Here, the absolute tolerance of the torque for all measurements is $\pm 0.075 \mathrm{Nm}$.

At first, a measurement with a rather wide range of $i_{\mathrm{s}}^{d}$ and a relatively big step size should be made, to get a rough idea of where the MTPC hyperbola lies. Thereafter, a second measurement with a concentrated range and much smaller step size can be done.

Figure 7a shows the first vague measurement with a shaft speed of $200 \mathrm{rpm}$, where the overall efficiency is plotted over the direct current $i_{\mathrm{s}}^{d}$. It can be seen that the efficiency

$$
\eta=\frac{P_{\mathrm{dc}}}{P_{\mathrm{s}}}=\frac{u_{\mathrm{dc}} i_{\mathrm{dc}}}{\omega_{\mathrm{s}} m_{\mathrm{s}}}
$$

changes a lot, especially at a low torque. $P_{\mathrm{s}}$ is the mechanical power at the shaft and $\omega_{\mathrm{s}}$ is the angular speed of the shaft. It is apparent that the point of maximum efficiency lies between $0 \mathrm{~A}$ and $-3 \mathrm{~A}$. Consequently, the more detailed measurements are done in this range. The results with the measured curve of the maximum efficiency are shown in the next section, where three methods are compared.

Despite the nearly constant temperature, speed, and torque throughout the measurement, the efficiency over the change of the direct current $i_{\mathrm{s}}^{d}$ is not sufficiently smooth to properly determine the point of maximum efficiency. Therefore, the measurement is done several times and the resulting efficiency is averaged. Furthermore, a polynomial of second order is used for fitting the averaged data points. The second order is chosen because the copper losses, which mainly cause the change in efficiency, are proportional to the square of $i_{\mathrm{s}}^{d}$, as seen in Equation (7). The blue line in Figure $7 \mathrm{~b}$ shows the averaged efficiency of three measurements at a constant torque of $-10 \mathrm{Nm}$. The dashed red line is the fitted polynomial, where the point of maximum efficiency or maximum output power is used for the curve of the maximum efficiency. 


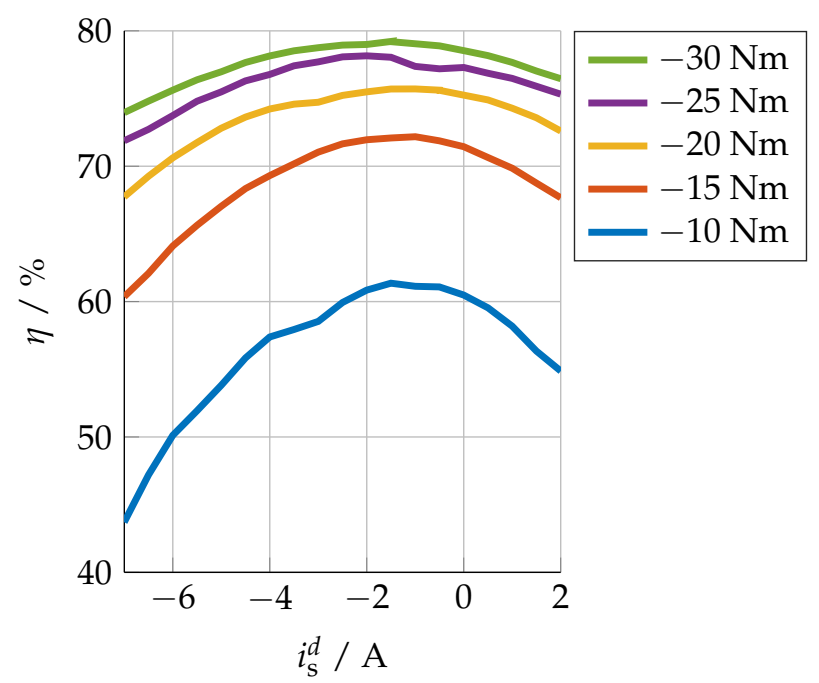

(a)

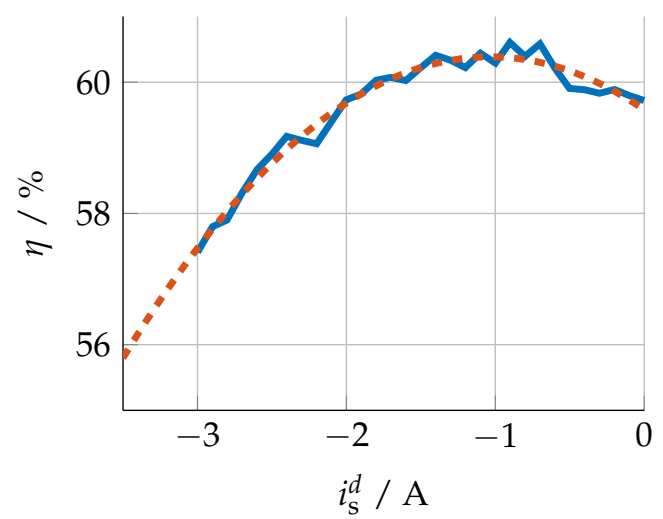

(b)

Figure 7. Measured efficiency over the direct current for a shaft speed of $200 \mathrm{rpm}$. (a) Roughly measured efficiency for different constant torques. (b) Measured efficiency ( - ) and fitted polynomial of second order $(-=-)$ over the direct current $i_{\mathrm{s}}^{d}$ for a constant torque of $-10 \mathrm{Nm}$.

\section{Implementation and Measurements}

In this section, the results of the previously described three methods, MTPC with linear or nonlinear flux linkages and the developed measurement method for loss minimization, are presented and compared.

\subsection{Setup of the Test Bench}

For all methods, certain measurements are necessary. They can be done on a test bench, where the machine under test (DUT) is mechanically connected to a drive machine (prime mover). This allows the machine to be driven at different operation points.

The used test bench was built to test electrical machines as generators. Therefore, it was not possible to drive the machine in motor mode. Typically, the DC-link of the inverter for the drive machine and the machine under test are coupled. Due to different voltage levels of the inverter electronics, this was not possible in the case at hand. The setup of the test bench is illustrated in Figure 8a.

The drive machine (DM) was a $5.5 \mathrm{~kW}$ induction machine, which was speed-controlled by a B\&R ACOPOS Frequency Inverter (FI). The Device Under Test (DUT) was a permanent-magnet synchronous machine. The electrical machine was in a housing with an integrated gear box, bearing, and sealing. The current control of this machine was done by the corresponding Voltage Source Inverter (VSI), developed by SINN Power GmbH. The controller was implemented on a 16-bit dsPIC microcontroller made by Microchip with an on-chip Pulse Width Modulation (PWM) unit which generated the stator voltage. The stator current and other measured quantities were sampled by the 10-bit Analog to Digital Converter (ADC). The measured stator voltages were filtered with analog filters, which were integrated in the VSI. Rotor position sensing was carried out by hall sensors in the machine. Through a Controller Area Network (CAN), reference currents could be transferred, and measured quantities of the inverter were sent to the Programmable Logic Control (PLC). The PLC made by B\&R performed the data acquisition, controlled the measurement sequence, provided a user interface to configure the measurements, sent the reference current to the inverter, and set the speed of the drive machine's frequency inverter. The PLC had an ADC module with a 16-bit resolution, where the torque and speed from the Torque Sensor (TS) DRBK-100-n, made by ETH-Messtechnik, could be measured. The DC-link voltage $u_{\mathrm{dc}}$ and current $i_{\mathrm{dc}}$ were measured in an equal manner. 
The Measurement Unit (MU) was a simple operational amplifier circuit which amplified the DC-link voltage and current for the ADC modules of the PLC. The DC-link current Was measured indirectly over the shunt resistor $R_{\mathrm{m}}$. The PLC also had an input module to measure the temperature with a simple Pt1000 sensor in different spots. One temperature sensor was located between the stator windings, to observe the operation point during the measurements. The Active Load (AL) PLI3260, produced by $\mathrm{H} \& \mathrm{H}$, controlled the DC-Link voltage $u_{\mathrm{dc}}$ to be constant. It can be assumed that it behaved as a constant voltage source which takes the power of the DC-link. A picture of the test bench is shown in Figure 8 b.

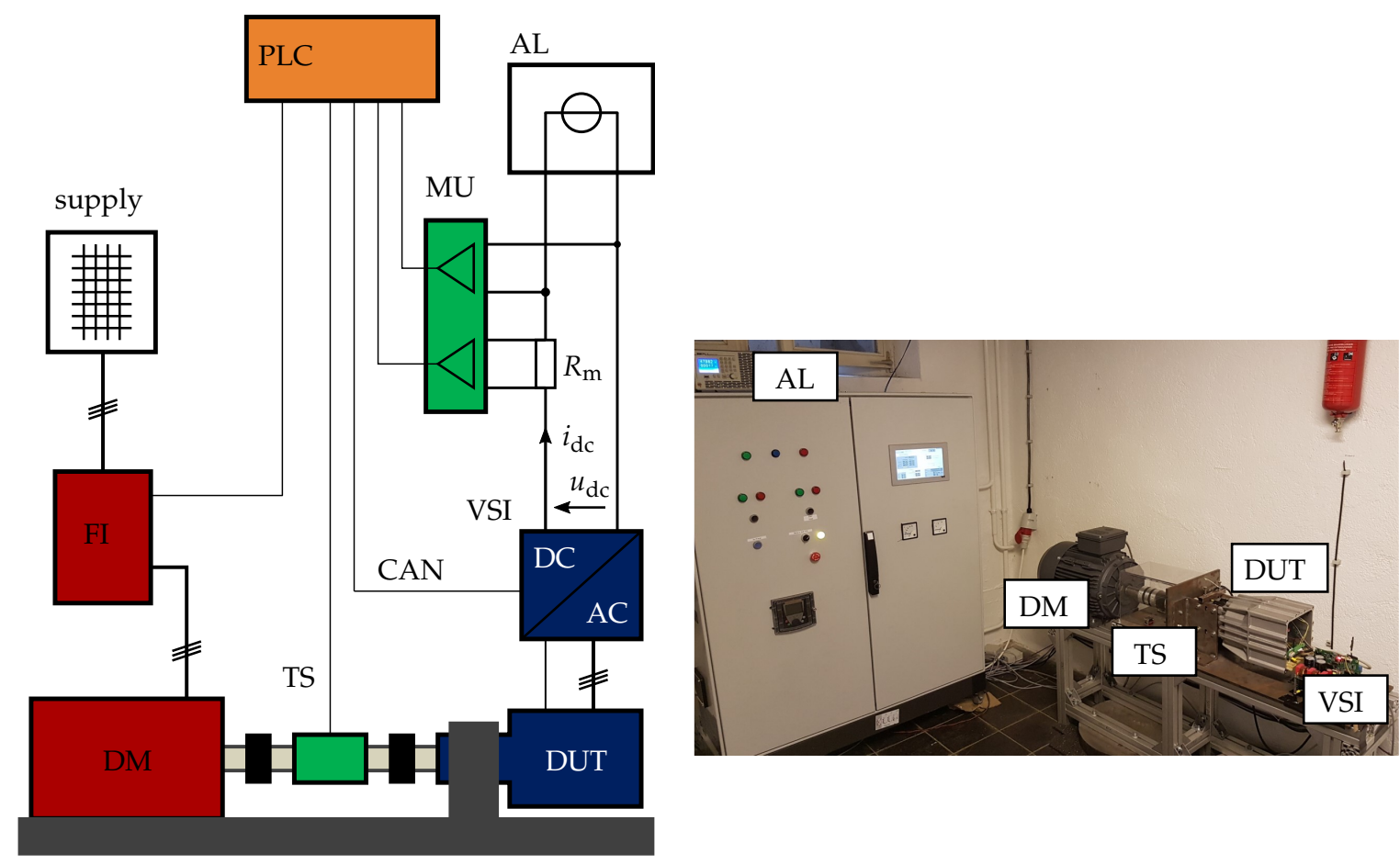

(a)

(b)

Figure 8. Illustration of the test bench. (a) Schematics of the test bench; and (b) Photograph of the test bench.

\subsection{Measurement Results}

Figure 9 shows the results of the three previously presented methods. The black lines in Figure 9a are the torque contour lines which were measured directly. They fit well to the calculated contour lines based on the flux linkage, if friction is considered. The blue MTPC hyperbola is calculated with the linearised flux linkages, as presented in Section 3.1. The red line is the interpolation of the points with the maximum torque per current ratio based on the measured, nonlinear flux linkages. Both results are very similar, since the machine under investigation shows no strong nonlinearity in the flux linkage maps, as shown in Figure 5. The yellow, violet, and green lines show the measured trajectories with the maximum efficiency of the torque contour lines, with shaft speeds at $100 \mathrm{rpm}, 200 \mathrm{rpm}$, and $300 \mathrm{rpm}$, respectively.

In Figure $9 \mathrm{~b}$, the green line shows the fitted efficiency over the current $i_{\mathrm{s}}^{d}$ for a shaft speed of $300 \mathrm{rpm}$ and a constant torque of $-15 \mathrm{Nm}$. The dashed black line is the measured efficiency. The computed points for linear and nonlinear flux linkages, where the amplitude of the current vector is minimal, are marked with a blue and a red cross, respectively. The point of maximum efficiency is marked with a red diamond.

The results of the MTPC methods differ from the developed method, as the ratio of DC-link power $P_{\mathrm{dc}}$ to mechanical power $P_{\mathrm{s}}$ in the shaft is used for the calculations and, thus, the actual point of 
maximum efficiency is obtained. Consequently, the influences of inverter and iron losses are also taken into account. Moreover, errors, such as misalignment of the rotor angle and delay, are compensated for by this method. The iron losses are the main reason that the measured curves are further to the left and not where the current vector has its minimum amplitude.

The steady-state electric model of the PMSM with iron losses is shown in Figure 10, where $R_{\mathrm{s}, \mathrm{Fe}}^{d}$ and $R_{\mathrm{s}, \mathrm{Fe}}^{q}$ are the iron loss resistances $[15,16,27]$. Due to these resistances, the stator currents are divided into the magnetization currents $i_{\mathrm{s}, \mathrm{m}}^{k}=\left(i_{\mathrm{s}, \mathrm{m}}^{d}, i_{\mathrm{s}, \mathrm{m}}^{q}\right)^{\top}$, which cause the torque and the iron loss currents $i_{\mathrm{s}, \mathrm{Fe}}^{k}=\left(i_{\mathrm{s}, \mathrm{Fe}}^{d} i_{\mathrm{s}, \mathrm{Fe}}^{q}\right)^{\top}$.

$$
i_{\mathrm{s}}^{d} / \mathrm{A}
$$

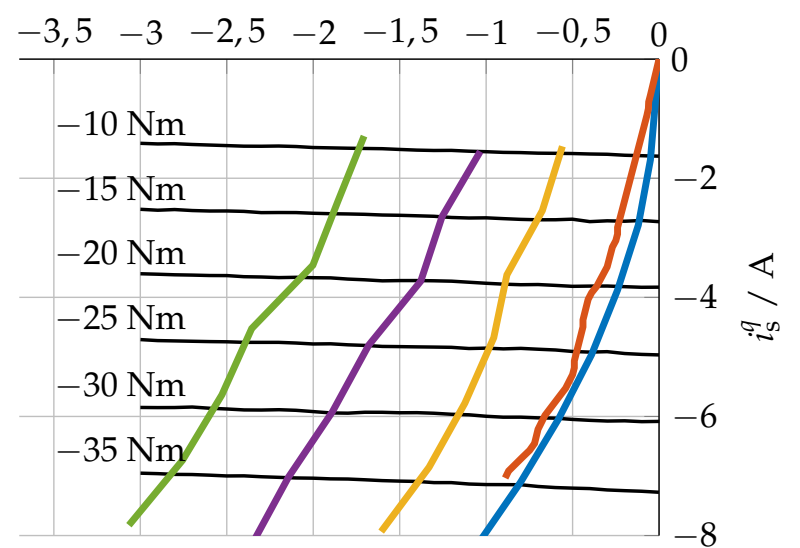

(a)

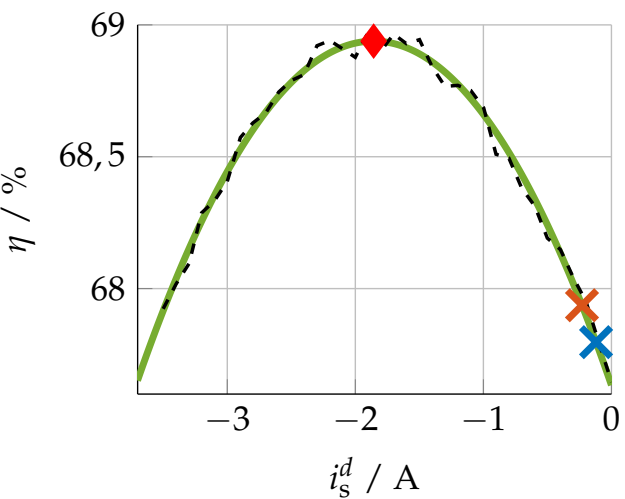

(b)

Figure 9. Comparison of the three presented methods. (a) Measured torque contour lines (-) and resulting trajectories for the two MTPC methods with linear approximated $(-)$ ) and nonlinear $(-)$ flux linkages and the measured trajectories with the maximum efficiency for different shaft speeds of $100 \mathrm{rpm}(-), 200 \mathrm{rpm}(-)$, and $300 \mathrm{rpm}(-)$ in the $(d, q)$-plane. (b) Efficiency ( -$)$ for a shaft speed of $300 \mathrm{rpm}$ and a constant torque of $-15 \mathrm{Nm}$ and the two points of MTPC for linear approximated $(x)$ ) and nonlinear $(x)$ flux linkages and the point of maximum efficiency $(\checkmark)$.
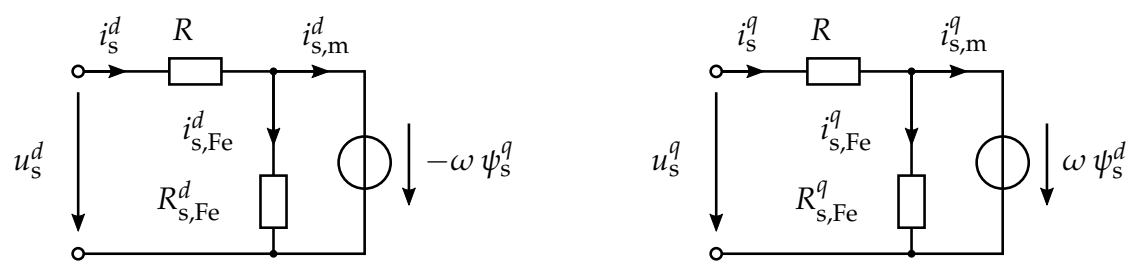

Figure 10. Steady-state electric model of the Permanent-Magnet Synchronous Machine (PMSM) with iron losses.

The voltage over the iron loss resistances depends on the rotor speed and the flux linkages. The flux linkages change with the magnetization currents, which, in turn, affects the voltage and thus the iron losses with

$$
P_{\mathrm{Fe}}=P_{\mathrm{Fe}}^{d}+P_{\mathrm{Fe}}^{q}=\frac{\left(\omega \psi_{\mathrm{s}}^{q}\right)^{2}}{R_{\mathrm{s}, \mathrm{Fe}}^{d}}+\frac{\left(\omega \psi_{\mathrm{s}}^{d}\right)^{2}}{R_{\mathrm{s}, \mathrm{Fe}}^{d}} .
$$

As shown in Figure 5a,b, the flux linkage $\psi_{\mathrm{s}}^{d}$ is reduced when the current $i_{\mathrm{s}}^{d}$ becomes more negative. With a reduced flux linkage $\psi_{\mathrm{s}}^{d}$, the iron loss $P_{\mathrm{Fe}}^{q}$ reduces as well. Therefore, it makes senses to allow more copper losses if iron losses, and thus the overall losses, are reduced. 
With higher speed, and thus higher induced voltage, the trajectories are shifted to the left, where a more negative current $i_{\mathrm{s}}^{d}$ gives the optimum compromise between iron and copper losses. Because of this, the trajectories of the maximum efficiency change with speed. For implementation, these results can be stored in a two-dimensional lookup table, where the optimal current vector is computed from the desired torque and the rotor speed. If the different trajectories show a simple correlation, a corresponding mathematical description can reduce the memory requirements.

As the results show, the maximum efficiency of the DUT can be achieved only if iron losses are considered, even at low rotor speeds. With MTPC, iron losses are neglected, which is why the maximum efficiency cannot be achieved.

\section{Conclusions}

The theory of MTPC is explained and it is shown that minimizing the amplitude of the current vector for constant torque increases the efficiency, even in generator operation. The influence of the MOSFETs in the voltage source inverter is considered.

To take nonlinearities in the flux linkages into account, the flux linkage maps are measured with a simple, industrial-like test bench. The MTPC hyperbola is computed, based on the linear approximation of the flux linkages and the nonlinear flux linkage maps.

Finally, a method is presented which allows direct measurement of the current vector with loss minimization and maximum efficiency, which also includes iron losses. It has been shown that the iron losses (of the considered machine) cannot be neglected if the maximum efficiency is to be achieved. This procedure is not dependent on a certain machine, and can be used for all kinds of electrical setups. If the flux linkage maps and the iron losses cannot easily be measured, because stator voltages cannot be determined or the resolution of the measurement equipment is not good enough, this method provides a feasible and simple alternative.

Author Contributions: Conceptualization, S.K. and C.M.H.; methodology, S.K. and C.M.H.; software, S.K.; validation, S.K. and C.M.H.; formal analysis, S.K. and C.M.H.; writing-original draft preparation, S.K.; writing-review and editing, C.M.H.; visualization, S.K.; supervision, C.M.H.

Funding: This research received no external funding.

Conflicts of Interest: The authors declare no conflict of interest.

\section{References}

1. Eldeeb, H.; Hackl, C.M.; Horlbeck, L.; Kullick, J. A unified theory for optimal feedforward torque control of anisotropic synchronous machines. Int. J. Control 2017, 1-30. [CrossRef]

2. Schröder, D. Elektrische Antriebe-Regelung von Antriebssystemen, 4th ed.; Springer: Berlin/Heidelberg, Germany, 2015.

3. Rang, G.; Lim, J.; Nam, K.; Ihm, H.B.; Kim, H.G. A MTPA Control Scheme for an IPM Synchronous Motor Considering Magnet Flux Variation Caused by Temperature. In Proceedings of the Nineteenth Annual IEEE Applied Power Electronics Conference and Exposition, 2004 (APEC '04), Anaheim, CA, USA, 22-26 February 2004; Volume 3, pp. 1617-1621. [CrossRef]

4. Jung, S.; Hong, J.; Nam, K. Current Minimizing Torque Control of the IPMSM Using Ferrari's Method. IEEE Trans. Power Electron. 2013, 28, 5603-5617. [CrossRef]

5. Hoang, K.D.; Wang, J.; Cyriacks, M.; Melkonyan, A.; Kriegel, K. Feed-forward Torque Control of Interior Permanent Magnet Brushless AC Drive for Traction Applications. In Proceedings of the 2013 International Electric Machines Drives Conference, Chicago, IL, USA, 12-15 May 2013; pp. 152-159. [CrossRef]

6. Mekri, F.; Elghali, S.B.; Benbouzid, M.E.H. Fault-Tolerant Control Performance Comparison of Three- and Five-Phase PMSG for Marine Current Turbine Applications. IEEE Trans. Sustain. Energy 2013, 4, 425-433. [CrossRef] 
7. Mekri, F.; Charpentier, J.; Benelghali, S.; Kestelyn, X. High Order Sliding mode optimal current control of five phase permanent magnet motor under open circuited phase fault conditions. In Proceedings of the 2010 IEEE Vehicle Power and Propulsion Conference, Lille, France, 1-3 September 2010; pp. 1-6. [CrossRef]

8. Kestelyn, X.; Semail, E. A Vectorial Approach for Generation of Optimal Current References for Multiphase Permanent-Magnet Synchronous Machines in Real Time. IEEE Trans. Ind. Electron. 2011, 58, 5057-5065. [CrossRef]

9. Bolognani, S.; Petrella, R.; Prearo, A.; Sgarbossa, L. Automatic Tracking of MTPA Trajectory in IPM Motor Drives Based on AC Current Injection. IEEE Trans. Ind. Appl. 2011, 47, 105-114. [CrossRef]

10. Kim, S.; Yoon, Y.; Sul, S.; Ide, K. Maximum Torque per Ampere (MTPA) Control of an IPM Machine Based on Signal Injection Considering Inductance Saturation. IEEE Trans. Power Electron. 2013, 28, 488-497. [CrossRef]

11. Sun, T.; Wang, J.; Chen, X. Maximum Torque Per Ampere (MTPA) Control for Interior Permanent Magnet Synchronous Machine Drives Based on Virtual Signal Injection. IEEE Trans. Power Electron. 2015, 30, 5036-5045. [CrossRef]

12. Ahmed, A.; Sozer, Y.; Hamdan, M. Maximum Torque per Ampere Control for Interior Permanent Magnet Motors using DC Link Power Measurement. In Proceedings of the 2014 IEEE Applied Power Electronics Conference and Exposition-APEC 2014, Fort Worth, TX, USA, 6-20 March 2014; pp. 826-832. [CrossRef]

13. Armando, E.; Bojoi, R.I.; Guglielmi, P.; Pellegrino, G.; Pastorelli, M. Experimental Identification of the Magnetic Model of Synchronous Machines. IEEE Trans. Ind. Appl. 2013, 49, 2116-2125. [CrossRef]

14. Mink, F.; Kubasiak, N.; Ritter, B.; Binder, A. Parametric Model and Identification of PMSM Considering the Influence of Magnetic Saturation. In Proceedings of the 2012 13th International Conference on Optimization of Electrical and Electronic Equipment (OPTIM), Brasov, Romania, 24-26 May 2012; pp. 444-452. [CrossRef]

15. Kellner, S.L.; Seilmeier, M.; Piepenbreier, B. Impact of Iron Losses on Parameter Identification of Permanent Magnet Synchronous Machines. In Proceedings of the 2011 1st International Electric Drives Production Conference, Nuremberg, Germany, 28-29 September 2011; pp. 11-16. [CrossRef]

16. Richter, J.; Dollinger, A.; Doppelbauer, M. Iron Loss and Parameter Measurement of Permanent Magnet Synchronous Machine. In Proceedings of the 2014 International Conference on Electrical Machines (ICEM), Berlin, Germany, 2-5 September 2014; pp. 1635-1641. [CrossRef]

17. Morimoto, S.; Tong, Y.; Takeda, Y.; Hirasa, T. Loss Minimization Control of Permanent Magnet Synchronous Motor Drives. IEEE Trans. Ind. Electron. 1994, 41, 511-517. [CrossRef]

18. Uddin, M.N.; Zou, H.; Azevedo, F. Online Loss Minimization Based Adaptive Flux Observer for Direct Torque and Flux Control of PMSM Drive. In Proceedings of the 2014 IEEE Industry Application Society Annual Meeting, Vancouver, BC, Canada, 5-9 October 2014; pp. 1-7. [CrossRef]

19. Barisa, T.; Sumina, D.; Kutija, M. Comparison of Maximum Torque per Ampere and Loss Minimization Control for the Interior Permanent Magnet Synchronous Generator. In Proceedings of the 2015 International Conference on Electrical Drives and Power Electronics (EDPE), Tatranska Lomnica, Slovakia, 21-23 September 2015; pp. 497-502.

20. Pairo, H.; Shoulaie, A. Effective and simplified method in maximum efficiency control of interior permanent magnet synchronous motors. IET Electr. Power Appl. 2017, 11, 447-459. [CrossRef]

21. Dirscherl, C.; Hackl, C.; Schechner, K. Modellierung und Regelung von modernen Windkraftanlagen: Eine Einführung. In Elektrische Antriebe—Regelung von Antriebssystemen; Schröder, D., Ed.; Springer: Berlin/Heidelberg, Germany, 2015; Chapter 24, pp. 1540-1614.

22. Richter, J.; Gemaßmer, T.; Doppelbauer, M. Predictive Current Control of Saturated Cross-Coupled Permanent Magnet Synchronous Machines. In Proceedings of the 2014 International Symposium on Power Electronics, Electrical Drives, Automation and Motion, Ischia, Italy, 18-20 June 2014; pp. 830-835. [CrossRef]

23. Wittig, B. Verbesserung des Schalt- und Betriebsverhaltens von Leistungs-MOSFETs mit niedriger Spannungsfestigkeit und hoher Stromtragfähigkeit durch Optimierung der Treiberschaltung. Ph.D. Thesis, Christian-Albrechts-Universität zu Kiel, Kiel, Germany, 2012.

24. Wintrich, A.; Nicolai, U.; Tursky, W.; Reimann, T. Applikationshandbuch Leistungshalbleiter, 2nd ed.; ISLE Verlag: Ilmenau, Germany, 2015.

25. Hackl, C.M.; Kamper, M.J.; Kullick, J.; Mitchell, J. Current control of reluctance synchronous machines with online adjustment of the controller parameters. In Proceedings of the 2016 IEEE 25th International Symposium on Industrial Electronics (ISIE), Santa Clara, CA, USA, 8-10 June 2016; pp. 153-160. [CrossRef] 
26. Hackl, C.M. Non-Identifier Based Adaptive Control in Mechatronics; Springer International Publishing: Basel, Switzerland, 2017.

27. Xu, L.; Yao, J. A Compensated Vector Control Scheme of a Synchronous Reluctance Motor Including Saturation and Iron Losses. IEEE Trans. Ind. Appl. 1992, 28, 1330-1338. [CrossRef]

(C) 2019 by the authors. Licensee MDPI, Basel, Switzerland. This article is an open access article distributed under the terms and conditions of the Creative Commons Attribution (CC BY) license (http:/ / creativecommons.org/licenses/by/4.0/). 